\title{
Formulation Development of Generic Omeprazole 20 mg Enteric Coated Tablets
}

\author{
Christopher Oswald Migoha1,2, Eliangiringa Kaale², Godliver Kagashe ${ }^{3}$ \\ ${ }^{1}$ Tanzania Food and Drugs Authority, Dar es Salaam, Tanzania \\ ${ }^{2}$ Pharm R\&D Lab, School of Pharmacy, Muhimbili University of Health and Allied Sciences, Dar es Salaam, \\ Tanzania \\ ${ }^{3}$ Department of Pharmaceutics, School of Pharmacy, Muhimbili University of Health and Allied Sciences, \\ Dar es Salaam, Tanzania \\ Email: christophermigoha@yahoo.com
}

Received 5 May 2015; accepted 17 July 2015; published 21 July 2015

Copyright @ 2015 by authors and Scientific Research Publishing Inc. This work is licensed under the Creative Commons Attribution International License (CC BY). http://creativecommons.org/licenses/by/4.0/

(c) (i) Open Access

\section{Abstract}

Omeprazole is a potent proton pump inhibitor with powerful inhibition of secretion of gastric juice. Oral site-specific drug delivery systems have recently attracted a great interest for the local treatment of bowel disease and for improving systemic absorption of drugs which are unstable in the stomach. However, microenvironment in the gastrointestinal tract and varying absorption mechanisms cause hindrance for the formulation and optimization of oral drug delivery. The objective of the study was to develop and optimize enteric coating process for omeprazole tablets. Different batches of core tablets were sub coated, one set sub coated with opadry and another with a mixture of light magnesium oxide, magnesium stearate and absolute alcohol omeprazole magnesium. Seal coating was applied by using opadry to achieve certain weight gain and to protect omeprazole from acidic coating polymers. A comparative dissolution test was performed. The variation of thickness and diameter were observed to be minimal with a weight gain of $3 \%-4 \%$ of enteric polymer. Disintegration test showed that in each tested batch the enteric coated layer remained intact in $0.1 \mathrm{~N} \mathrm{HCl}$ for 2 hours and when exposed to alkaline media of phosphate buffer pH 6.8, it dissolved within few minutes. Dissolution release was $98.8 \%$ to $102.4 \%$ within two hours when the product was exposed to phosphate buffer pH 6.8 after 2 hours. The similarity and dissimilarity factors were calculated and observed to be 54 to 61 and 4 to 5 respectively. Therefore a simple and good enteric coating process was developed and tested with potential for transfer this technology into local pharmaceutical industries using cheap and easily available materials.

\section{Keywords}

Omeprazole Magnesium, Enteric Coating, Tablets, Kollicoat (Methacrylic Acid/Ethyl Acrylate 


\section{Copolymers) (MAE)}

\section{Introduction}

Omeprazole, 5-methoxy-2(((4-methoxy-3,5-dimethyl-2-pyridinyl)methyl)sulfinyl)-1H-benzimidazole (Figure 1 ), is a potent inhibitor of gastric acid secretion. It shows powerful inhibitory action against secretion of gastric juice and is used in treatment of duodenal and gastric ulcers [1]. However, omeprazole is susceptible to degradation/transformation in acid reacting and neural media [1].

The in vitro degradation of omeprazole is catalyzed by acidic compounds and is stabilized in mixtures with alkaline compounds. Moisture and organic solvents also affect the stability of omeprazole. From the data of stability studies of omeprazole, it is obvious that an oral dosage form must be protected from contact with acid gastric juice in order to reach the small intestine without degradation [1]-[3].

Human pharmacological studies showed that the rate of release of omeprazole from solid dosage form could influence the total extent of absorption of omeprazole to the general circulation [2]. A fully bioavailable dosage form of omeprazole must release the active drug rapidly in the proximal part of gastrointestinal canal [2].

The pharmaceutical dosage form with property of protecting omeprazole from contact with gastric acid must be developed, that is core. The core must be enteric coated. The core developed must be alkaline in nature as most of available acid compounds will not favor stability of omeprazole [4].

Coating polymer, such as Eudragit L 30, hydroxyl propyl methyl cellulose phthalate, cellulose acetate phthalate and acryl EZE ${ }^{\circledR}$ (Aqueous Acrylic Enteric System), to achieve 5\% weight gain may be considered [5]. This is due to the fact that they permit the dissolution of the coating and the active drug contained in the core once in the proximal part of the small intestine. They also allow some diffusion of water of gastric acid through them into the cores, at the time when the dosage form resides in the stomach before it is emptied into the small intestine [5] [6].

It is expected that the diffused water of gastric juice will dissolve parts of the core in the close proximity of the enteric coating layer and form an alkaline solution in the coated dosage form. The alkaline solution is expected to interfere with the enteric coating and eventually dissolve it [6].

\section{Materials and Methods}

\subsection{Equipments}

The equipments include: Tabular mixer (Analytical Technology, Bangalore, India), Korsh EK 01 tablet press machine (Germany), auto coater (Glatt, Germany), Monsanto type tablet hardness tester (IEC, Mumbai, India), Roche Fribilator (electro lab, Bangalore, India), single pan balance (Shimadzu,AX200, Japan), Disintegration Apparatus USP (Elecrolab, Bangalore, India), graduated cylinder (Fisher Scientific, Germany), sieve analyzer (Endecott's, Germany), glass bottles (Fisher Scientific, Germany), HPLC (Shimazdu, Japan), ERWEKA TBH machine (Heusenstamm, Germany), Dissolution Test Apparatus (Elecro Lab, TDT-08L, Mumbai, India.

\subsection{Materials}

The materials include: Omeprazole magnesium (Metrochem API Private Limited, Hyderabad, India), Sodium laurl sulphate (LOBA Chemie Pvt. Ltd., Mumbai, India), Lactose (OXFORD Laboratories, Mumbai, India), Avicel ph 102 (Shandong Liaocheng Ehua Medicine Co. Ltd., Shandong, China), Maize starch (OXFORD Laboratories,<smiles>COc1ccc2[nH]c(C(=O)N(Cc3ncc(C)c(OC)c3C)c3nc4cc(OC)ccc4[nH]3)nc2c1</smiles> 
Mumbai, India), Water aerosil 200 (Shandong Liaocheng Ehua Medicine Co. Ltd., Shandong, China) and Magnesium stearate (Hozhou Zhanwang Pharmaceutical Co. Ltd., Huzhou, China), Kollicoat ${ }^{\circledR}$ MAE Polymers (BASF, Germany). Other reagents and solvents were procured commercially and were of pharmaceutical and analytical grade. Application of the entire materials (Active ingredient and excipients) has been described in Table 1 .

In vitro analysis of the prepared tablets was carried out as per the requirements of enteric coated tablets as specified in official pharmacopoeia [7].

\subsection{Experimental Methods}

\subsubsection{Preparation of Core Tablets}

Since omeprazole magnesium is moisture sensitive material, all the processing steps including weighing, mixing, direct compression and coating was carried out at $30^{\circ} \mathrm{C} \pm 2^{\circ} \mathrm{C}$ and $60 \% \pm 5 \% \mathrm{RH}$ [8].

The materials for preparation of core tablets for three different as listed in Table 2 were accurately weighed and then sodium laurly sulphate was sieved through $0.5 \mathrm{~mm}$ sieve. Omeprazole magnesium, sodium laurly sulphate and maize starch together were placed in a tubular mixer and mixed for 10 minutes. Another mixture of maize starch, Lactose and water aerosil 200 were place in a tubular mixer and mixed for 10 minutes and then the two mixtures together with magnesium stearate was sieved through 0.8 sieves and mixed for 5 minutes. Thereafter the mixtures were compressed in Korsh EK 01 Tablet press machine using 9 mm-R15 punch to form tablets. Three batches were prepared for each formulation.

Table 1. Formulation ingredients of Omeprazole $20 \mathrm{mg}$ enteric coated tablets.

\begin{tabular}{|c|c|c|}
\hline Category & Ingredients & Application \\
\hline \multicolumn{3}{|c|}{ Core Tablets Ingredients } \\
\hline & Omeprazole Magnesium & Active \\
\hline & Sodium Lauryl Sulphate & Lubricant \\
\hline & Tablottose (Lactose) & Binder \\
\hline & Avicel ph 102 & Disintegrant \\
\hline & Maize starch & Diluent \\
\hline & Water Aerosil 200 & Glidant \\
\hline & Magnesium Stearate & Lubricant \\
\hline \multicolumn{3}{|c|}{ Sub Coating I Ingredients } \\
\hline & OPADRY White (HPMC) & \\
\hline & Phosphate Buffer $\mathrm{pH}$ & \\
\hline \multicolumn{3}{|c|}{ Sub Coating II Ingredients } \\
\hline & Cellular Powder & Water Insoluble Polymer \\
\hline & Light Magnesium Oxide & Stabilizer/Alkalizer \\
\hline & Magnesium Stearate & Anti-Sticking Agent \\
\hline & Absolute Alcohol & Solvent \\
\hline \multicolumn{3}{|c|}{ Enteric Coating Ingredients } \\
\hline & Kollicoat MAE $30 \mathrm{DP}^{*}$ & Enteric Coating Polymer \\
\hline & Propylene Gycol & Plasticizer \\
\hline & Water & Solvent \\
\hline
\end{tabular}

${ }^{*}$ Kollicoat MAE 30 DP is Methacrylic acid copolymer. 


\subsubsection{In Process Quality Control (IPQC) of Core Tables}

Before sub coating of core tablets, IPQC tests was conducted. The parameters tested were weight variation, thickness, diameter, hardness, friability and disintegration time as per USP Pharmacopoeia [7].

\subsubsection{Sub Coating of Core Tablets}

Sub coating was done for the purpose of acting as moisture barrier to core tablet and preventing interaction between acidic labile omeprazole and acidic enteric coating material. Two sets of sub coating materials were considered (Sub coating I and Sub coating II) as depicted in Table 1 and Table 2. The Sub Coating material for I was prepared by weighed $2.5 \mathrm{mg}$ of OPADRY and dissolved it in phosphate buffer $\mathrm{pH} 7.4$ to obtain $0.25 \% \mathrm{w} / \mathrm{v}$ of OPADRY solution. The obtained solution was atomized from the top of the apparatus for coating of tablets with coating parameters shown in Table 3. The materials for preparation of Sub coating II were dispensed as depicted in Table 1 and Table 2 and dissolved in absolute alcohol. The mixture was stirred for 45 minutes till homogenous suspension was obtained and sifted through 0.5 sieve then sub coating was done as per set parameters in Table 3. The sub coating for those tablets was done in Glatt auto coater.

\subsubsection{Enteric Coating of Sub-Coated Tablets}

Enteric coating of sub coated tablets was done after accurately weighed ingredients of coating materials as depicted in Table 1 and Table 2. Propylene glycol was first dissolved in specified amount of water followed by stirring. Then Kollicoat MAE 30 DP was added while stirring. Machine parameters were as in Table 4. Sub

Table 2. Formulations details of Omeprazole $20 \mathrm{mg}$ enteric coated tablets.

\begin{tabular}{|c|c|c|c|c|c|c|}
\hline Formulations & OME 001 & OME 002 & OME 003 & OME 004 & OME 005 & OME 006 \\
\hline \multicolumn{7}{|l|}{ Core Tablets Ingredients (mg) } \\
\hline Omeprazole Magnesium & 20.0 & 20.0 & 20.0 & 20.0 & 20.0 & 20.0 \\
\hline Sodium Lauryl Sulphate & 2.0 & 2.0 & 1.9 & 2.0 & 1.9 & 2.1 \\
\hline Tablottose (Lactose) & 76.0 & 76.0 & 76.0 & 76.0 & 76.0 & 76.0 \\
\hline Avicel ph 102 & 60.0 & 60.0 & 60.0 & 60.0 & 60.0 & 60.0 \\
\hline \multicolumn{7}{|l|}{ Maize starch } \\
\hline Water Aerosil 200 & 0.6 & 0.6 & 0.6 & 0.6 & 0.6 & 0.6 \\
\hline Magnesium Stearate & 1.4 & 1.4 & 1.4 & 1.4 & 1.4 & 1.4 \\
\hline \multicolumn{7}{|l|}{ Sub Coating 1 Ingredients } \\
\hline OPADRY White (HPMC) & 0.008 & 0.008 & 0.008 & 0.008 & 0.008 & 0.008 \\
\hline Phosphate Buffer $\mathrm{pH}$ & QS & QS & QS & QS & QS & QS \\
\hline \multicolumn{7}{|l|}{ Sub Coating II Igredients } \\
\hline Cellulose Powder & 0.96 & 0.96 & 0.96 & 0.96 & 0.96 & 0.96 \\
\hline Light Magnesium Oxide & 0.77 & 0.77 & 0.77 & 0.77 & 0.77 & 0.77 \\
\hline Magnesium Stearate & 0.77 & 0.77 & 0.77 & 0.77 & 0.77 & 0.77 \\
\hline Absolute Alcohol & QS & QS & QS & QS & QS & QS \\
\hline \multicolumn{7}{|l|}{ Enteric Coating Material } \\
\hline Kollicoat MAE 30 DP* & $70 \%$ & $70 \%$ & $70 \%$ & $70 \%$ & $70 \%$ & $70 \%$ \\
\hline Propylene glycol & $4.2 \%$ & $4.2 \%$ & $4.2 \%$ & $4.2 \%$ & $4.2 \%$ & $4.2 \%$ \\
\hline Water & $25.8 \%$ & $25.8 \%$ & $25.8 \%$ & $25.8 \%$ & $25.8 \%$ & $25.8 \%$ \\
\hline
\end{tabular}

*Kollicoat MAE 30 DP is Methacrylic acid copolymer. 
Table 3. Process Parameters to be controlled during sub coating.

\begin{tabular}{ccc}
\hline Process Parameters & Formulation I & Formulation II \\
\hline Pan speed & $2 \mathrm{RPM}$ & $2 \mathrm{RPM}$ \\
Inlet air temperature & $40^{\circ} \mathrm{C} \pm 5^{\circ} \mathrm{C}$ & $50^{\circ} \mathrm{C} \pm 5^{\circ} \mathrm{C}$ \\
Outlet air temperature & $30^{\circ} \mathrm{C} \pm 5^{\circ} \mathrm{C}$ & $40^{\circ} \mathrm{C} \pm 5^{\circ} \mathrm{C}$ \\
Air volume & $360 \mathrm{~m}^{2} / \mathrm{h}$ & $360 \mathrm{~m}^{2} / \mathrm{h}$ \\
Nozzle diameter & $1.0 \mathrm{~mm}$ & $1.0 \mathrm{~mm}$ \\
Atomizing air pressure & $2.0 \mathrm{bar}$ & $2.0 \mathrm{bar}$ \\
Spraying rate & $1.5 \mathrm{ml} / \mathrm{min}$ & $1 \mathrm{gm} / \mathrm{min}$ \\
Coating level & $3 \%$ & $3 \%$ \\
\hline
\end{tabular}

\begin{tabular}{cc|}
\hline Table 4. Process parameters to be controlled during enteric coating. \\
\hline Process Parameters & Set Limit \\
\hline Pan speed & $2 \mathrm{RPM}$ \\
Inlet air temperature & $50^{\circ} \mathrm{C} \pm 5^{\circ} \mathrm{C}$ \\
Outlet air temperature & $30^{\circ} \mathrm{C} \pm 5^{\circ} \mathrm{C}$ \\
Air volume & $360 \mathrm{~m}^{2} / \mathrm{h}$ \\
Nozzle diameter & $1.0 \mathrm{~mm}$ \\
Atomizing air pressure & $2.0 \mathrm{bar}$ \\
Spraying rate & $30-35 \mathrm{~g} / \mathrm{min}(1.5 \mathrm{ml} / \mathrm{Min})$ \\
Coating level & $3 \%-4 \%$ \\
\hline
\end{tabular}

coated tablets were pre heated in coating pan for 10 minutes at $40^{\circ} \mathrm{C} \pm 5^{\circ} \mathrm{C}$. The tablets were coated in Glatt auto coater to achieve $3 \%$ to $4 \%$ weight gain.

\subsubsection{Evaluation of Coated Tablets}

Enteric coated tablets of omeprazole were evaluated for weight variation, Thickness, Diameter, Hardness, Friability and Disintegration time as per USP Pharmacopoeia. The formulations assessed by content uniformity test and dissolution testing by USP Type I Basket apparatus at $100 \mathrm{RPM}$ in $900 \mathrm{ml}$ of $0.1 \mathrm{~N} \mathrm{HCl}$ for 120 minutes and afterwards in phosphate buffer of 6.8 for 60 minutes [7].

\section{Results and Discussion}

All of the studied physical properties were within the acceptable range with narrow variation and complied with the pharmacopoeia specifications for both core and coated tablets. The parameters tested were diameter, hardness, friability and weight variation. The shape and the size of tablets for all batches were found to be within the acceptable limit. For core tablets diameter for all tablets range between 9.37 to $9.39 \mathrm{~mm}$ and hardness of all formulations lies within the range of 66 to $68 \mathrm{~N}$. All formulations passes friability test as the percentage weight loss was within pharmacopeia limit, i.e. NMT $1 \%$. The weight variation and drug content of all the formulations were found to be within the acceptable limit.

For coated tablets, three batches were taken and each was divided into two batches, i.e. OME 001, OME 002 \& OME 003 divided into OME 001A, OME 001B, OME 002A, OME 002B, OME 003A and OME 003B. Where the A ones were of sub-coated I and of B were of sub-coated II. There was a weight gain of $3 \%-4 \%$ of the enteric polymer. The thickness and diameter of 20 coated tablets from each formulation was determined using ERWEKA TBH machine and average value were calculated and evaluated as per USP 30. The hardness of 
tablets ranges from $67 \mathrm{~N}$ to $73 \mathrm{~N}$. The variation of thickness and diameter was observed to be minimal. The percentage of friability of tablets ranges from $0.339 \%$ to $0.468 \%$ which was in acceptable range. The percentage of drug content of the formulated tablets when assayed was $100.1 \%$ to $105.9 \%$ which is within specification. Results showed no significant differences. Results for evaluation of core tablets are summarized in Table 6 .

\subsection{In Process Quality Control (IPQC) Tests for Core Tablets}

Tablets were prepared by direct compression technique. The results of in process quality control tests are listed in Table 5 and they show that the product was firm enough to withstand handling without breaking and not so hard that the disintegration time can be prolonged. Therefore all batches are considered to be optimized core tablets for further experiment.

\subsection{Evaluation of Coated Tablets}

The friability results of coated tablets indicate good mechanical resistance of tablets. Results showed no significant differences. Results for evaluation of coated tablets are summarized in Table 6.

Disintegration Test show that in all six tablets in each tested batch the enteric coated layer remained intact in $0.1 \mathrm{~N} \mathrm{HCl}$ for 2 hours but there were few signs of cracking and little swelling observed. The enteric coating layer of tablets started to imbibe the alkaline media of phosphate buffer $\mathrm{pH} 6.8$ and completely removed approximately at 30 minutes and afterwards tablets were completely dissolved within 50 minutes.

\subsection{In Vitro Drug Release}

The in vitro dissolution of all formulated batches (i.e. OME 001A, OME 002A, OME 003A, OME 001B, OME 002B \& OME 003B) was studied in $0.1 \mathrm{~N} \mathrm{HCl}$ for 2 hours and 1 hour in phosphate buffer $\mathrm{pH}$ 6.8. The results observed showed that for all batches there was physical resistance to the acid medium with few signs of cracking and swelling and the drug released after two hours was found to be within specified limit (Table 7 and Figure 2).

Table 5. Evaluation test of Omeprazole core tablets.

\begin{tabular}{|c|c|c|c|c|c|c|c|}
\hline Batches & $\begin{array}{l}\text { Diameter } \\
\text { (mm) }\end{array}$ & $\begin{array}{l}\text { Thickness } \\
\text { (mm) }\end{array}$ & Friability (\%) & Hardness (N) & $\begin{array}{c}\text { Weight } \\
\text { uniformity (mg) }\end{array}$ & Assay (\%) & $\begin{array}{l}\text { Disintegration } \\
\text { time (Min) }\end{array}$ \\
\hline OME 001 & $9.37 \pm 0.03$ & $4.28 \pm 0.11$ & 0.369 & 66.75 & $221.55 \pm 6$ & $105.2 \pm 1.1$ & NMT 5 \\
\hline OME 002 & $9.37 \pm 0.03$ & $4.28 \pm 0.14$ & 0.387 & 59.9 & $221.55 \pm 5$ & $104.5 \pm 1.1$ & NMT6 \\
\hline OME 003 & $9.38 \pm 0.05$ & $4.28 \pm 0.11$ & 0.339 & 67 & $221.55 \pm 5$ & $105.2 \pm 1.1$ & NMT 5 \\
\hline OME 004 & $9.38 \pm 0.05$ & $4.28 \pm 0.11$ & 0.350 & 70 & $221.55 \pm 5$ & $105.9 \pm 0.1$ & NMT 7 \\
\hline OME 005 & $9.37 \pm 0.03$ & $4.28 \pm 0.11$ & 0.386 & 68 & $221.55 \pm 6$ & $99 \pm 1.1$ & NMT6 \\
\hline OME 006 & $9.37 \pm 0.03$ & $4.28 \pm 0.11$ & 0.370 & 60 & $221.55 \pm 7$ & $99 \pm 1.1$ & NMT 5 \\
\hline
\end{tabular}

NB: All values are expressed as mean \pm SD $(n=20)$.

Table 6. Evaluation test of Omeprazole enteric coated tablets.

\begin{tabular}{|c|c|c|c|c|c|c|}
\hline IPQC Parameters & OME 001A & OME 001B & OME 002A & OME 002B & OME00 3A & OME 00 3B \\
\hline Diameter (mm) & $9.4 \pm 0.05$ & $9.42 \pm 0.05$ & $9.38 \pm 0.05$ & $9.3 \pm 0.05$ & $9.41 \pm 0.06$ & $9.48 \pm 0.06$ \\
\hline Thickness (mm) & $5.77 \pm 0.11$ & $5.78 \pm 0.11$ & $6.02 \pm 0.10$ & $6.0 \pm 0.10$ & $5.97 \pm 0.11$ & $5.90 \pm 0.11$ \\
\hline Friability (5) & 0.369 & 0.387 & 0.339 & 0.350 & 0.468 & 0.384 \\
\hline Hardness (N) & 69 & 70 & 67 & 73 & 68 & 72 \\
\hline Weight uniformity & $229.6 \pm 10$ & $231.3 \pm 10$ & $231.1 \pm 10$ & $231.9 \pm 10$ & $231.8 \pm 10$ & $231.7 \pm 10$ \\
\hline Assay (\%) & $105.2 \pm 1.1$ & $104.5 \pm 0.0$ & $105.5 \pm 0.1$ & $105.9 \pm 0.1$ & $100.1 \pm 0.3$ & $100.1 \pm 0.3$ \\
\hline
\end{tabular}

NB: All values are expressed as mean \pm SD $(n=20)$. 
Table 7. Drug release profile.

\begin{tabular}{ccccccc}
\hline \% Drug Release & OME 001A & OME 002A & OME 003A & OME 001B & OME 002B & OME 003B \\
\hline $\begin{array}{c}\text { 0.1N HCl within 2 Hrs } \\
\text { Phosphate buffer pH 6.8 after 2 Hrs }\end{array}$ & 0.00 & 0.00 & 0.00 & 0.00 & 0.00 & 0.00 \\
02:10 & & & & & & \\
02:20 & 34.07 & 22.18 & 23.08 & 68.9 & 70.2 & 93.0 \\
$02: 40$ & 52.99 & 35.88 & 37.07 & 78.8 & 79.23 & 95.0 \\
$02: 50$ & 72.03 & 52.78 & 53.57 & 90.25 & 91.45 & 98.3 \\
$03: 00$ & 86.5 & 77.05 & 78.68 & 98.9 & 99.1 & 101.3 \\
\hline
\end{tabular}

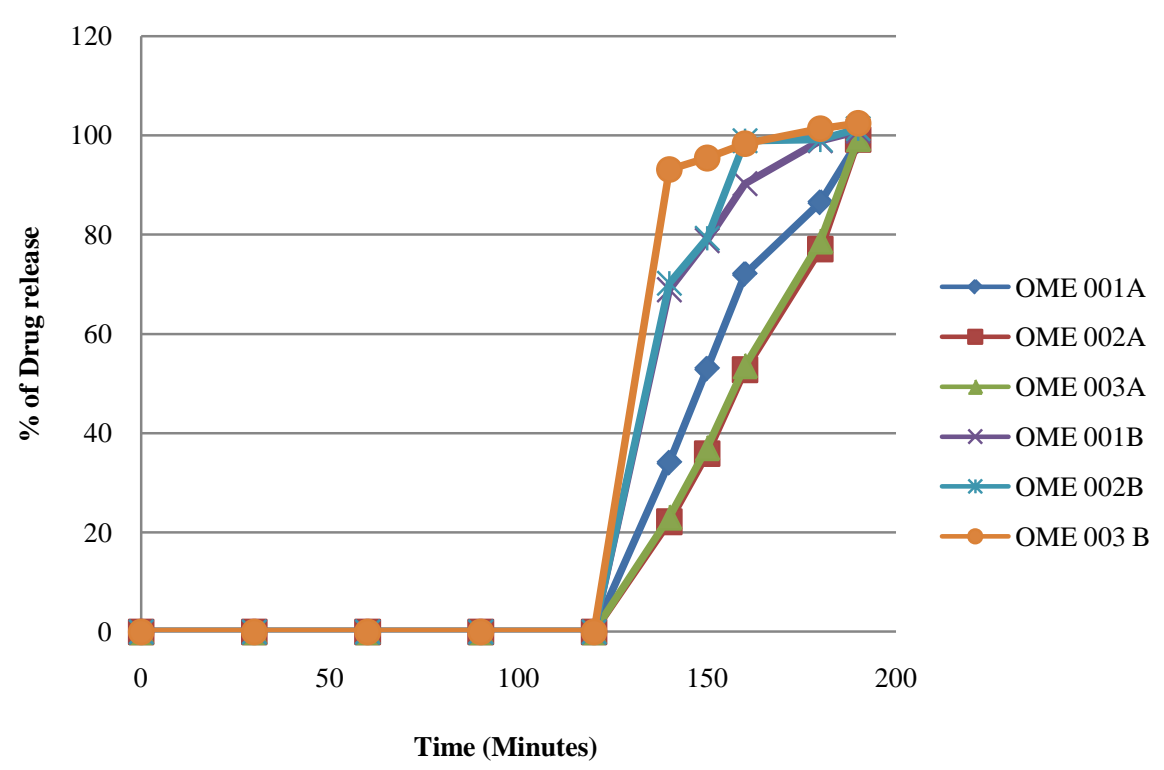

Figure 2. Drug release profile of formulated omeprazole enteric coated tablets in 0.1N HCL and phosphate buffer 6.8 .

Therefore all batches were selected as optimized batches because they have shown better drug release even though the formulation sub coated with opadry solution has a better dissolution profile i.e. OME 001 - 003A and consumed less concentration of enteric coating polymer.

\subsection{Comparison of Developed Generic Omeprazole Magnesium Enteric Coated with Marketed Products}

The selected batches i.e. OME 001 and OME 002 were compared with Pilorsec capsules $20 \mathrm{mg}$ and Losec Mups $20 \mathrm{mg}$. Pilorsec capsules was dropped from the study after the capsules dissolved immediately in the acid and noted that omeprazole powder and sodium bicarbonate was present in the capsules without any protection. The disintegration time and release profile of selected formulations and Losec is given in Table 8. From the results it was concluded that the formulated generic products had similar disintegration profile, drug content and percentage release with marketed product.

\subsection{Similarity and Dissimilarity Studies}

The Similarity Factor $\left(\mathrm{F}_{2}\right.$ value) and Dissimilarity Factor $\left(\mathrm{F}_{1}\right)$ were calculated using equation of similarity by using a simple model independent approach to compare dissolution profile between Formulated products OME 001A \& OME 002B and marketed product Losec MUPS $20 \mathrm{mg}$ [9]. The equations used were as follows: 
Table 8. Dissolution test profile of prepared formulations with Losec Mups $20 \mathrm{mg}$.

\begin{tabular}{cccccccccccc}
\hline Time (Minutes) & 0 & 30 & 60 & 90 & 120 & 130 & 140 & 150 & 160 & 180 & 190 \\
\hline OME 001A & 0 & 0 & 0 & 0 & 0 & 58 & 85.9 & 94.5 & 98.4 & 99.8 & 101.1 \\
OME 001B & 0 & 0 & 0 & 0 & 0 & 45 & 87 & 96 & 99 & 99.5 & 100.82 \\
Losec Mups & 0 & 0 & 0 & 0 & 0 & 72 & 88.2 & 96 & 98.7 & 99.3 & 100 \\
\hline
\end{tabular}

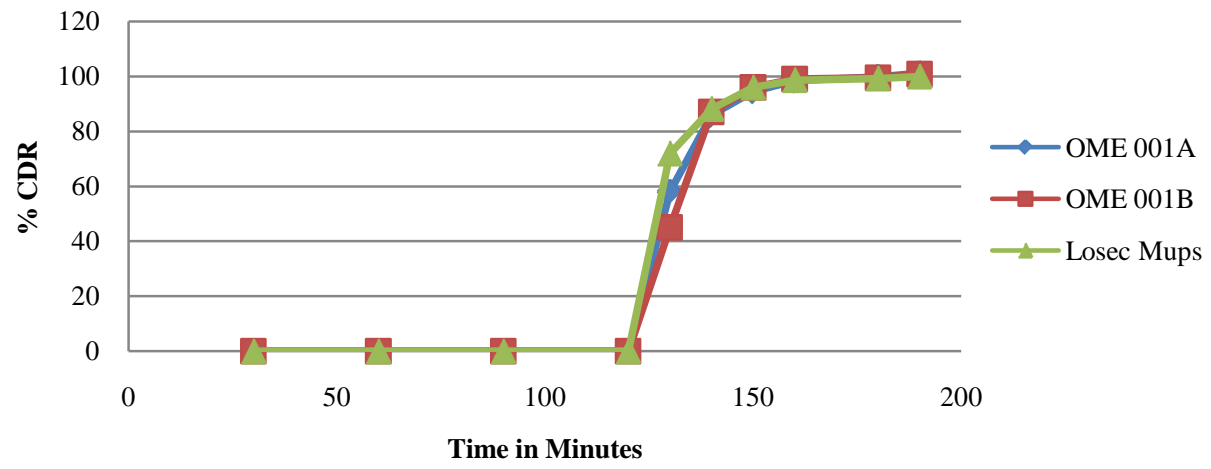

Figure 3. Comparative release profile between Losec Mups, OME 001A \& OME 001B.

1) $\mathrm{F}_{1}=\left\{\left[\mathrm{S}_{\mathrm{t}=1}^{\mathrm{n}}\left(\mathrm{R}_{\mathrm{t}}-\mathrm{T}_{\mathrm{t}}\right)\right] /\left[\mathrm{S}_{\mathrm{t}=1}^{\mathrm{n}} \mathrm{R}_{\mathrm{t}}\right]\right\} * 100$

2) $\mathrm{F}_{2}=50 \log \left\{\left[1+(1 / \mathrm{n}) \mathrm{S}^{\mathrm{t}=1 \mathrm{n}}\left(\mathrm{R}_{\mathrm{t}}-\mathrm{T}_{\mathrm{t}}\right)^{2}\right]^{-0.5} * 100\right\}$

By using the formula [10], $\mathrm{F}_{2}$ value was calculate and found to be 61 for OME 001A and 54 for comparison with OME 002B. Therefore the $F_{2}$ values ensure the sameness or equivalence of two curves. The respective $F_{1}$ values were found to be 4 and 5 respectively. Using the mean dissolution values from the two curves at each time interval the different factor $F_{1}$ and similarity Factor $F_{2}$ were calculated using the above equations, the results showed that the curves were similar to $F_{1}$ which were close to zero i.e. between 0 and 15 and $F_{2}$ values close to 100 as the values were greater than 50 (Figure 3).

\section{Conclusion}

A simple and good enteric coated omeprazole magnesium tablets with potential for transfer into local industries in Tanzania was developed and tested. Opadry white coating (HPMC) (Sub-coating I) and a mixture of cellulose powder, light magnesium oxide, magnesium stearate and absolute alcohol (Sub-coating II) were used for sub-coating. The enteric coating was successfully done by using Kollicoat ${ }^{\circledR}$ Methacrylic acid AE 30 DP (Methacrylic acid/ethyl acrylate copolymers) which is an aqueous dispersion.

\section{Acknowledgements}

Migoha C.O is thankful to Tanzania Food \& Drugs Authority for sponsoring the programme and for providing necessary facilities to carry out analysis work at its laboratory, also the School of Pharmacy for providing required facilities to carry out formulation development of the product.

\section{Conflict of Interests}

The authors declare that they have no conflict of interests regarding the publication of this article.

\section{References}

[1] Blanchi, A., Delchier, J.C., Soule, J.C., Payen, D. and Bader, J.P. (1982) Control of Acute Zollinger-Ellison Syndrome with Intravenous Omeprazole. Lancet, 2, 1223-1224. 
[2] Wurster, D.E. (1957) U.S Patent 2,799,241. Wisconsin Almini Research Foundation.

[3] Wurster, D.E. (1959) Air-Suspension Technique of Coating Drug Particles. A Preliminary Report. Journal of the American Pharmaceutical Association, 48, 451-454. http://dx.doi.org/10.1002/jps.3030480808

[4] Hardman, J.G., Limburd, L.E., Molinoff, P.B., Ruddon, R.W. and Gilman, A.G. (Eds.) (1996) Goodman \& Gilman’s The Pharmacological Basis of Therapeutics. 9th Edition, McGraw-Hill, New York.

[5] Nair, A.B., Gupta, R., Kumria, R., Jacob, S. and Attimarad, M. (2010) Formulation and Evaluation of Enteric Coated Tablets of Proton Pump Inhibitors. Journal of Basic and Clinical Pharmacy, 1, 215-221.

[6] Mäder, K., Bräunig, K., Meyer, K. and Kolter, K. (2005) Development and Stability Studies of Enteric Omeprazole Formulations Based on Kollicoat ${ }^{\circledR}$ MAE Polymers. BASF Aktiengesellschaft, Development Pharma Ingredients, Ludwigshafen.

[7] United States Pharmacopoeia (USP) 30 NF25.

[8] http://www.pharmpedia.com/Tablet:Tablet_coating

[9] Mukharya, A., Chaudhary, S., Bheda, A., Mulay, A., Mansuri, N. and Laddh, N. (2011) Stable and Bioequivalent Formulation Development of Highly Acid Labile Proton Pump Inhibitor: Rabeprazole. International Journal of Pharmaceutical Research and Innovation, 2, 1-8.

[10] FDA (2000) Guidance for Industry: Waiver of in Vivo Bioavailability and Bioequivalence Studies for Immediate-Release Solid Oral dosage Forms Based on a Biopharmaceutics Classification System. 